\title{
Modification induced by laser irradiation on physical features of plastics materials filled with nanoparticles
}

\author{
Cristina Scolaro ${ }^{1, *}$, Annamaria Visco $^{1,4}$, Lorenzo Torrisi ${ }^{2}$, Nancy Restuccia $^{2}$ and Eugenio Pedullà ${ }^{3}$ \\ ${ }^{1}$ Department of Engineering, University of Messina, C.da Di Dio, 98166 Messina, Italy \\ ${ }^{2}$ Dept. of MIFT, University of Messina, V.le F. S. D’Alcontres 31, 98166 Messina, Italy \\ ${ }^{3}$ Dept. of General Surgery and Medical-Surgical Specialties, University of Catania, Via Plebiscito 628, 95124, Catania, Italy \\ ${ }^{4}$ Istituto per i Processi Chimico-Fisici CNR -IPCF, Viale Ferdinando Stagno d'Alcontres, 37 - 98158 MESSINA
}

\begin{abstract}
The Thermal Laser Welding (TLW) process involves localized heating at the interface of two pieces of plastic that will be joined. Polymeric materials of Ultra High Molecular Weight Polyethylene (UHMWPE), both pure and containing nanostructures at different concentrations (titanium and silver nanoparticles), were prepared as thin foils in order to produce an interface between a substrate transparent to the infrared laser wavelength and an highly absorbent substrate, in order to be welded by the laser irradiation. The used diode laser operates at $970 \mathrm{~nm}$ wavelength, in continuum, with a maximum energy of $100 \mathrm{~mJ}$, for times of the order of 1-60 s, with a spot of $300 \mu \mathrm{m}$ of diameter. The properties of the polymers and of nanocomposite sheets, before and after the laser welding process, were measured in terms of optical characteristics, wetting ability, surface roughness and surface morphology.
\end{abstract}

\section{Introduction}

Plastic material junctions are of great interest for polymeric industrial applications; for this reason welding technological processes needs to be studied and optimized in order to produce high aesthetic and resistant quality products. Moreover, the polymers can be welded with various experimental techniques. For some years, Trasmission Laser Welding (TLW) has a considerable role among the various junction methods, allowing to work with low mechanical and thermal loads, ensuring welds of excellent mechanical and aesthetic quality as no residues are present in the area of welding and the thermally altered area is very narrow.

All polymers commonly used for laser welding, under non-doping conditions, are more or less transparent in the visible and near infrared ranges. The most used lasers for the soldering process [1], are represented by continuous Diode laser, operating in the range 800$1000 \mathrm{~nm}$ wavelength [2], based on semiconductor pn junction, and the nanosecond $\mathrm{Nd}$ :YAG laser operating at $1064 \mathrm{~nm}$ fundamental frequency [3-5]. The addition of filling materials, such as pigments (fillers), to the polymer matrix provides the absorption of laser energy by the doped polymer in specific wavelength ranges.

One of the most popular polymers in the world, widely daily used, is the polyethylene, which is the raw material for food film, plastic bottles, pipes, packaging, sports goods, fabrics, furnishing accessories, toys, electronic applications, medical products, etc.

The generic formula for polyethylene is $\left(-\mathrm{C}_{2} \mathrm{H}_{4}-\right)_{\mathrm{n}}$, where $\mathrm{n}$ is the degree of polymerization. Although it has a simple basic chemical composition, there are many varieties (Low-Density Polyethylene - LDPE, HighDensity Polyethylene - HDPE, Linear Low-Density Polyethylene - LLDPE, Ultra-High-Molecular-Weight Polyethylene - UHMWPE, Ethylene Acrylic Acid EAA, Ethylene-Vinyl Acetate - EVA), whose thermal and mechanical properties vary according to the structure of the molecular chains, that make up and determine their different use. In any form it is used, its excellent features of good insulating, eco-compatible, corrosion-resistant, and others, make it always reliable in any circumstance.

For these reasons and beyond the most immediate application [6], polyethylene is a precious material especially in the world's most advanced sectors, such as industry, health [7] and energy, where, alongside advances and innovations in techniques already known and experienced, interesting perspectives emerge around new research topics, some of which are being tested and concerning this work. Great industrial interest is in fact directed toward the welding of plastics with different concentrations of nano-materials and ones that must be transparent for aesthetic reasons [8].

This investigation focused on the realization of welded joints of high molecular weight UHMWPE polyethylene and UHMWPE polyethylene doped with various concentrations of nanostructures (titanium ad silver) to make the absorbent material. The joints have been welded using a $970 \mathrm{~nm}$ wavelength laser diode. The great advantage of the diode laser is that it can be used as a pen and the welding process is very easy to obtain. Therefore, compact design and high-efficiency diode

Corresponding author: cscolaro@unime.it 
laser make it very interesting for practical and industrial applications for the adhesion of thermoplastic polymers. The properties of the polymers before and after the laser welding process were measured in terms of optical characteristics, wet ability of biocompatible solutions, surface roughness, surface morphology and surface composition (UH pure/ nanocomposites).

\section{Materials and Methods}

\subsection{Materials}

UHMWPE (Ticona-GUR 1020, $\rho=930 \mathrm{~kg} / \mathrm{m} 3, \mathrm{Mw} \approx$ $3 \times 106 \mathrm{~g} / \mathrm{mol}$ ) was mixed with silver nanostructures and titanium dioxide with spherical shape and diameter between $50-100 \mathrm{~nm}$, used as fillers in a quantity of $1 \%$ in weight (for titanium dioxide nanoparticles, UHNTiO) and $4 \%$ in weigth (for silver nanoparticles, UHNAg).

Considering the mechanical response of joints, here not shown in detail for brevity, just the $1 \%$ in weigth of $\mathrm{TiO}_{2}$ (UHNTiO1) and the 4\% of Ag nanoparticles (UHNAg4) have been chosen as nanocomposites fillers.

These nanofiller amounts showed the best shear strength among all the samples, with a measured value of $107 \mathrm{~N}$ for titanium dioxide nanoparticles and of $78 \mathrm{~N}$ for silver nanoparticles [9].

The different nanofiller types $\left(\mathrm{TiO}_{2} / \mathrm{Ag}\right)$ were dispersed in pure ethanol. The polymer-filler-solvent system was sonicated at room temperature for $2 \mathrm{~h}$. The solvent residue was then removed by stirring on a heat plate. The obtained nanocomposites were molded and pressed at $\mathrm{T}=200^{\circ} \mathrm{C} / 20$ minutes and $\mathrm{P}=200 \mathrm{~atm}$, obtaining $60 \mathrm{~mm} \mathrm{x}$ $60 \mathrm{~mm}$ and $0.5 \mathrm{~mm}$ thick sheets using thin film in Teflon $(123 \mu \mathrm{m}$ thick $)$ as detachable agents.

\subsection{Laser Irradiation}

The laser used for laser welding of polymeric joints, is a Diode Laser (Lamba Scientific - D5-Doctor Smile) operating at a wavelength of $970 \mathrm{~nm}, \mathrm{CW}(0.5-7 \mathrm{~W})$, maximum power $100 \mathrm{~mJ}$, for order times of 1-60 s, $300 \mu \mathrm{m}$ fiber optic diameter (Fig.1, left). No lens was used to focus the beam of the laser led to air at $25^{\circ} \mathrm{C}$ and at $1 \mathrm{~atm}$.
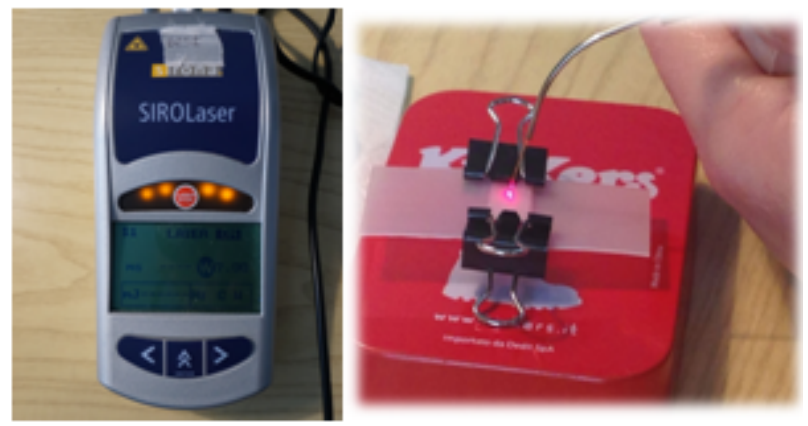

Fig. 1. Diode Laser (Lamba Scientific - D5-Doctor Smile)
The welded joints were obtained by partially overlapping polymeric sheets, white and black as in the sequence schematized in Fig.2.a (Single Lap, SL) and Fig.2.b (Double Lap, DL).

The external sheet is laser light transparent (pure UHMWPE) while the inner sheet laser is light absorbent (nanocomposite). Samples of laser irradiation have a rectangular geometry of $30 \mathrm{~mm} \times 20 \mathrm{~mm} \times 0.5 \mathrm{~mm}$ thick (Fig.3). Transparent and absorbent polymer sheets (at different filler percentages) are partially superimposed (for $0.8 \mathrm{~mm}$ lengths) and blocked by the use of two clipon tweezers (Fig.1, right), with the task of exerting the required force $(30 \mathrm{~N})$ [10] for a good welding process according to the scheme shown in Fig.3.
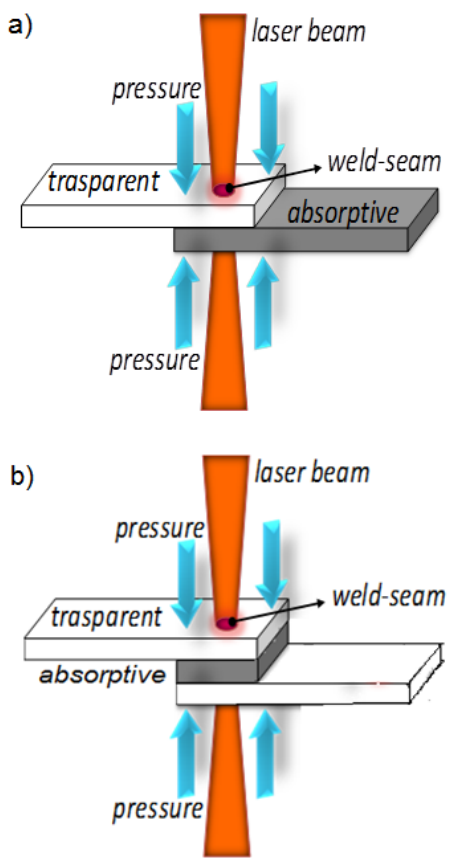

Fig. 2. a) Schematic of the system of laser welding in single lap (SL) or b) in double lap (DL).

A point geometry was created by the diode laser with an irradiation time of about 2 minutes per point for a total of 6 points (for both silver and titanium dioxide nanocomposites. Samples were investigated in the pure zone (zone 1, Fig.3) and just before the Heat Altered Zone (just before HAZ, zone 2 and zone 3, Fig.3).

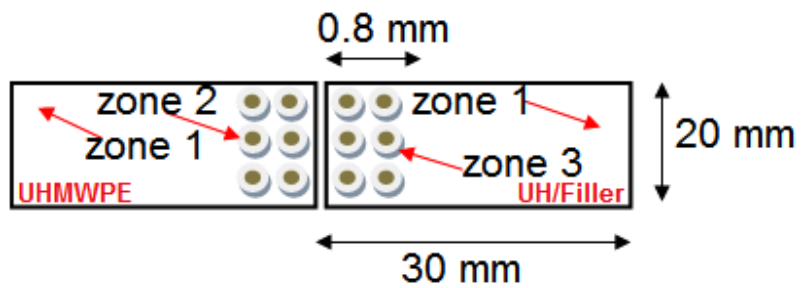

Fig. 3. Schematization of a point geometry created by diode laser and zones investigate. 


\subsection{Contact angle measurements}

The contact angle was evaluated by the wet ability of the nano-composite surface. Wet ability measurements were performed using the experimental setup shown in Fig.4.

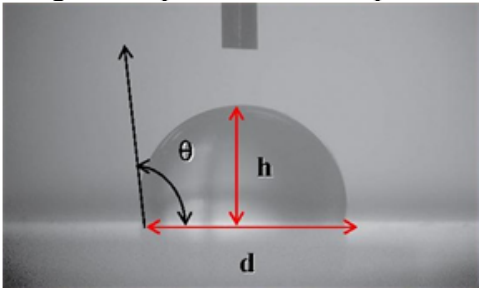

Fig. 4. Drop profile and contact angle determination.

By placing a drop of $1 \mu 1$ of distilled water at room temperature on the horizontal surface of the sample using a microlitric syringe (Hamilton, $10 \mu 1$ ), a video camera connected to the computer captures the image of the drop just deposited on the material and define, by means of software [11], the measurement of the base line of the drop from which the diameter $d(\mathrm{~mm})$ and the height $h(\mathrm{~mm})$ of the drop are obtained which are used to calculate the contact angle $\theta$ by the following formula [12]:

$$
\theta=2 \operatorname{arctg}(2 h / d)
$$

At a temperature of $\mathrm{T}=22^{\circ} \mathrm{C}, \mathrm{UR}=35 \%$ and $\mathrm{P}=1 \mathrm{~atm}$, six measurements of the contact angle of the distilled water at different points for each single sample were performed and then the average value was determined arithmetically.

\subsection{Roughness measurements}

The roughness measurements on the polyethylene sample surface were carried by using the Tencor P-10 surface profilometer with a micrometric movable tip loaded with a force of $1 \mathrm{mg}$ that scans the surface of the sample $[13,14]$. The system has a depth resolution of 10 $\mathrm{nm}$, a lateral resolution of $1 \mu \mathrm{m}$ and a scan surface speed of 100 m/s. The analysis is done using a diamond tip that touches the surface of the sample to follow the profile. A position transducer converts the tip movement into its height value. All information is transmitted to a computer connected to the instrument that shows the surface morphology of the sample. The tip of the instrument sweeps horizontally, depending on the requested sansion, and vertically due to a constant pressure within 1-5 mg. The vertically excursion recorded by an analogical-digital converter and plotted on the pc screen.

The surface roughness was measured using the average peak-to-peak distance of the roughness profile. The variations observed by measuring the contact angle of distilled water on nano-composites can be attributed to the heterogeneity of the surface determined by the roughness. The theory that explains the effect of surface roughness on the wet ability is described by Wenzel's equation [15]:

$$
\cos \theta_{w}=r \cos \theta_{i}
$$

Where $\theta_{W}$ is the angle of effective contact of a rough surface real, or angle of Wenzel, $r$ is the ratio between the actual area of the surface of the solid and the nominal one, and $\theta_{Y}$ is the contact angle of equilibrium of Young observed on a ideally smooth surface.

\section{Results and discussion}

Prior to perform the diode laser irradiation, surface wet ability and roughness tests were carried out on the pure and doped polyethylene UHMWPE matrix.

Wet ability tests performed on pure UH polyethylene and on $\mathrm{UH}$ with $1 \mathrm{wt} \% \quad \mathrm{TiO}_{2}$ show a tendency for hydrophilic behavior at nano-composite concentrations.

The contact angle measurement showed a change in the contact angle of pure UHMWPE (Fig.5.a): its value of $96^{\circ}$ decreases in both nano-composites. In fact it is of $94^{\circ}$ in the nano-composite filled with titanium dioxide (UHNTIO1, Fig.5.b) and of the $77^{\circ}$ in the nanocomposite filled with silver nanoparticles (UHNAg4, Fig.5.c). These values depend on the surface roughness of the material that changes from $2.06 \mu \mathrm{m}$ for pure UHMWPE (Fig.5.b), to $2.00 \mu \mathrm{m}$ for UHNTiO1 (Fig.5.d) and to $3.31 \mu \mathrm{m}$ for UHNAg4 (Fig.5.f). These measurements are affected of the error of the order ten percent.
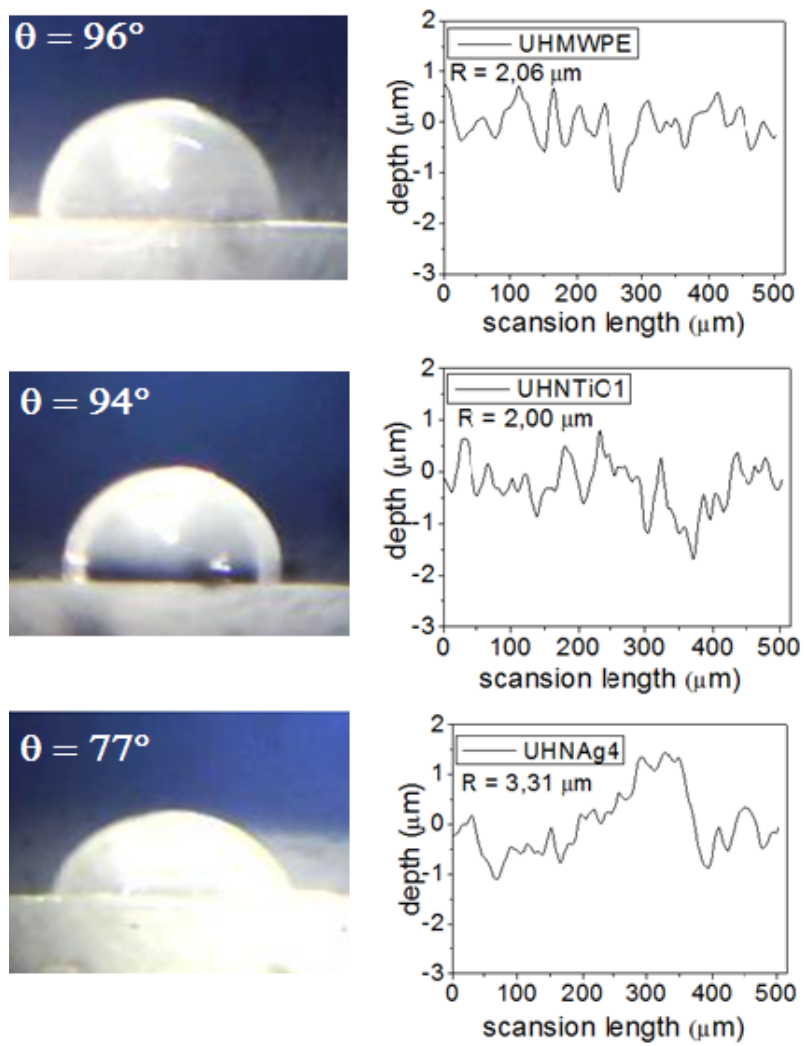

Fig. 5. Images of distilled water droplets and roughness profiles respectively of $a-b)$ UHMWPE pure, c-d) UHNTiO1 and d-e) UHNAg4.

Generally, profilometric measures have shown that the greater the amount of filling, the greater the roughness of the polymeric nano-composite. As previously mentioned, the roughness has a fundamental influence 
on the contact angle. In fact, the value of the contact angle $\theta$ decreases by increasing the surface roughness of the nano-composites, as shown in Fig.6.

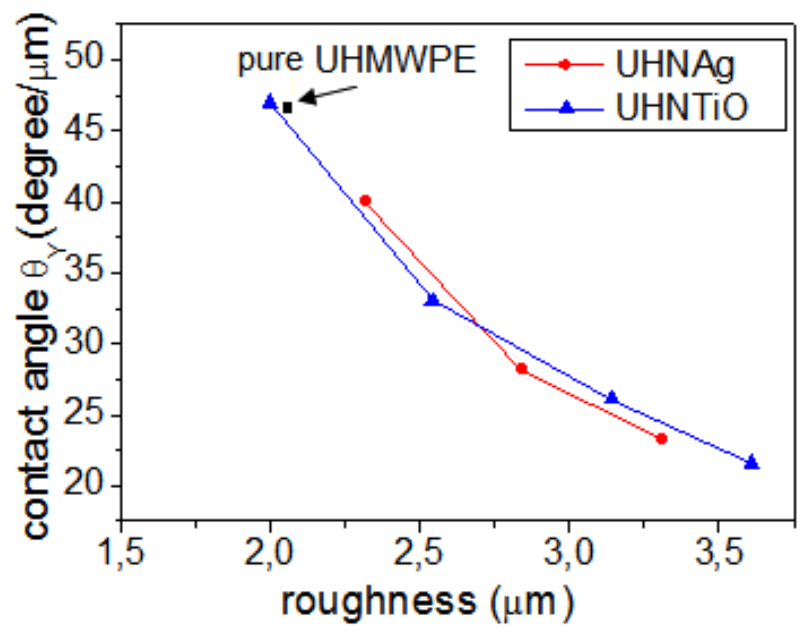

Fig. 6. Change the contact angle $v s$ the roughness of the nanomaterial.

This result confirms that the growth of filler in the polymer nano-composite makes its surface more irregularly increasing its surface roughness. The latter lowers the interfacing tension of the liquid drop, favouring its wet ability.

Morphological observation by optical microscope of the spot welded area, using the $\mathrm{TiO}_{2}$ nanoparticles, shows how laser irradiating the polymer melts the materials and changes its surface morphology (Fig.7).

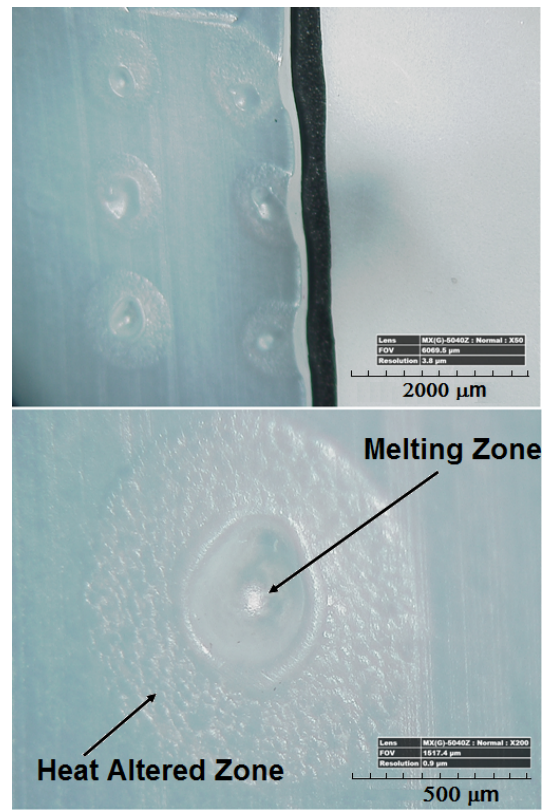

Fig. 7. Optical Microscope images, UHNTiO1 welding junctions (left) and a magnification particular of the melted and of the HAZ area (right).

Comparison of the contact angle pattern determined in the junction interface (UHMWPE pure and transparent and UH doped with fillers and absorbent) of the indicated materials ((NAg4 - NTiO1) are shown in
Fig.8. Figures 8.a and 8.e show the pictures of distilled water droplets, UHNTiO1 and UHNAg4 junctions respectively created with the Diode laser and determined just before the HAZ (UH doped with fillers and absorbent). Experimentally determined contact angles are $110^{\circ}$ for UHNTiO1 and $75^{\circ}$ for UHNAg4. Surface roughness values found are $1.53 \mu \mathrm{m}$ (UHNTiO1, Fig.8.b) and $3.04 \mu \mathrm{m}$ (UHNAg4, Fig.8.f).

Figures 8.c and 8.g show the pictures of distilled water droplets, UHNTiO1 and UHNAg4 junctions respectively created with the Diode laser and determined on the heat altered zone (UHMWPE pure and transparent). Experimentally determined contact angles are $138^{\circ}$ for UHNTiO1 and $94^{\circ}$ for UHNAg4. Surface roughness values found are $1.2 \mu \mathrm{m}$ (UHNTiO1, Fig.8.d) and 2.01 $\mu \mathrm{m}$ (UHNAg4, Fig.8.h).

The morphological study of the welded area shows that their physical properties depend on many factors.

The mechanical strength, uniformity, colour and roughness of the melted reinforcement, for example, depends on the time of irradiation, the thickness of the transparent polymer, the laser intensity, and the amount of fillers used in the absorbent polymer.
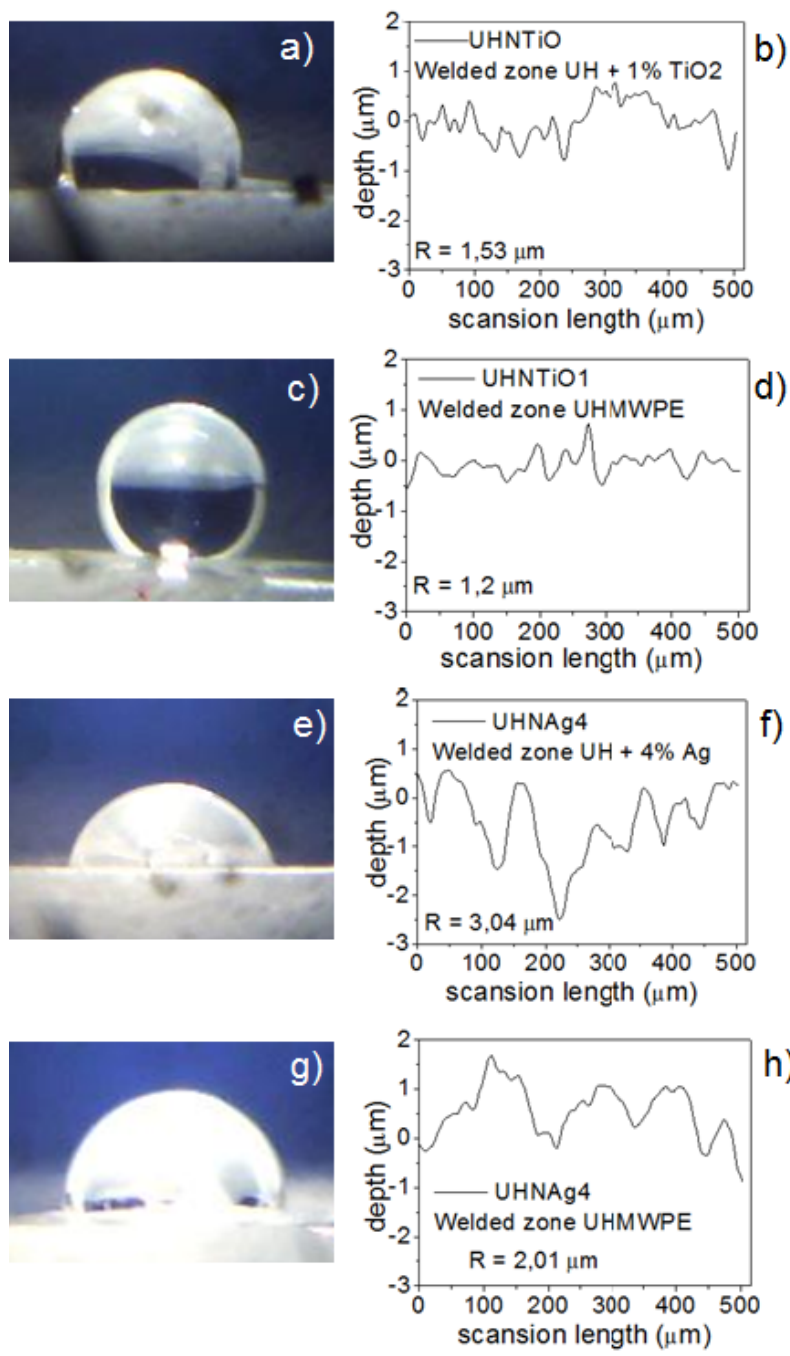

Fig. 8. Pictures of distilled water droplets and roughness profiles of the UHNTiO1 and UHNAg4 welding zones (just before the HAZ). 
Tables 1 summarize the wet ability and roughness values of the fusing zone interface of the joints UHNAg4 and UHNTiO1 created with the diode laser.

Table 1. Contact angle and roughness of the UHNTiO1 and UHNAg4 joints created with the Diode laser just before the HAZ.

\begin{tabular}{|c|c|c|c|c|c|c|}
\hline \multicolumn{7}{|c|}{ Contact angle and Roughness results for UHNTiO1 and UHNAg4 } \\
\hline $\begin{array}{c}\text { Welded } \\
\text { Joint }\end{array}$ & $\begin{array}{c}\text { Contact } \\
\text { angle } \\
\begin{array}{c}\text { Zone 1 } \\
\left({ }^{\circ}\right)\end{array}\end{array}$ & $\begin{array}{c}\text { Contact } \\
\text { angle } \\
\begin{array}{c}\text { Zone 2 } \\
\left({ }^{\circ}\right)\end{array}\end{array}$ & $\begin{array}{c}\text { Contact } \\
\text { angle } \\
\begin{array}{c}\text { Zone 3 } \\
\left({ }^{\circ}\right)\end{array}\end{array}$ & $\begin{array}{c}\text { Roughness } \\
\text { Zone 1 } \\
(\mu \mathrm{m})\end{array}$ & $\begin{array}{c}\text { Roughness } \\
\text { Zone 2 } \\
(\mu \mathrm{m})\end{array}$ & $\begin{array}{c}\text { Roughness } \\
\text { Zone 3 } \\
(\mu \mathrm{m})\end{array}$ \\
\hline UHNTiO1 & 94 & 138 & 110 & 2.00 & 1.2 & 1.53 \\
\hline UHNAg4 & 77 & 94 & 75 & 3.31 & 2.01 & 3.04 \\
\hline
\end{tabular}

The dependence of the contact angle (normalized to the surface roughness) by the roughness is shown in Fig.9. The angle values have been calculated according to the Wenzel equation (2) and measured just before the HAZ at the junction interface, both in the pure polyethylene and in the nano-composite. The contact angle decreases with increasing the surface roughness just before the HAZ for both materials. Furthermore, the lowest wet ability (hydrophobic feature) can be reached in the nanocomposite with low amounts of filler particles and, hence, of surface roughness, and viceversa. Considering the filler amounts of the tested nano-composites, the sample UHNTiO exhibited a lower roughness and so a higher hydrophobic character than the UHNAg one (see table I).
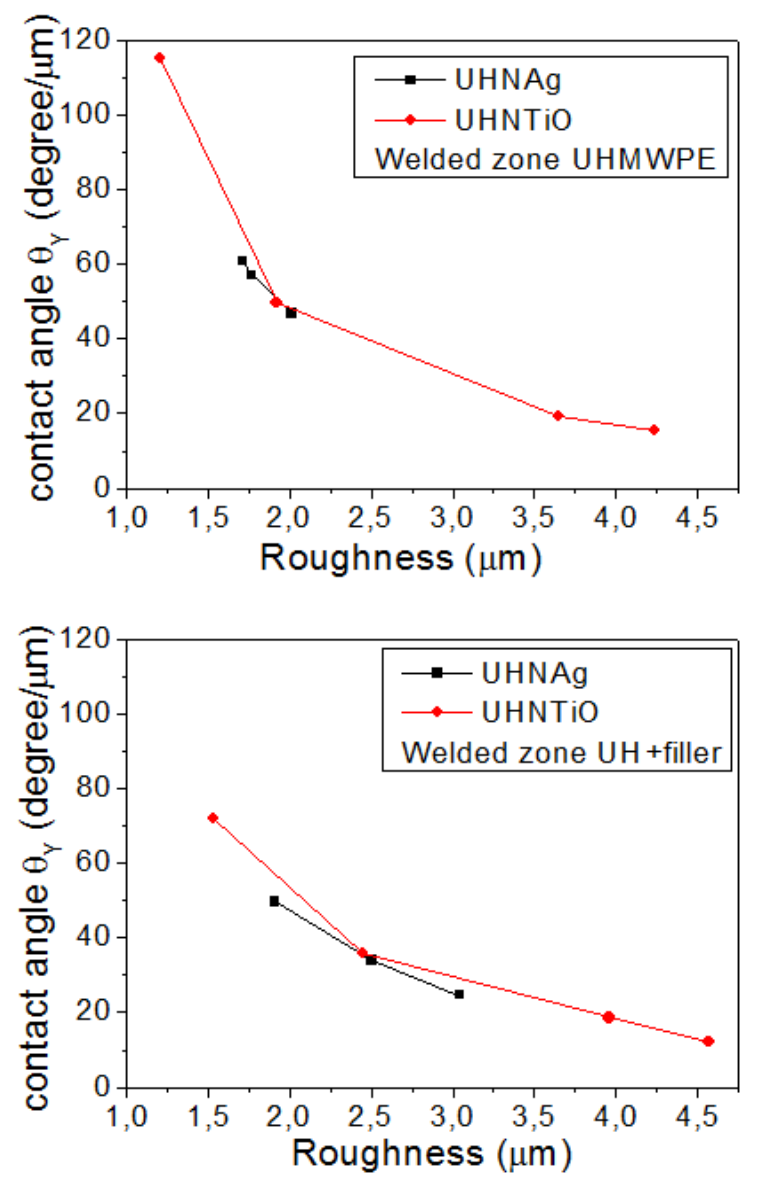

Fig. 9. Trend of contact angle $\theta_{\mathrm{Y}} v s$ roughness of the UHNTiO1 and UHNAg4 just before the HAZ.

\section{Conclusions}

Polymeric single and double lap joints were successfully welded with diode lasers source. The laser absorbent sheets were doped with different amount of nanomaterials (titanium and silver oxides). We have studied the surface features of the polymers, the optical absorbing properties, wetting ability and surface roughness. The tested nano-composite sheets, filled with titanium dioxide and silver nanoparticles can be usefull in order to have white color joint with also a low surface roughness and low damage and a quite hydrophobic character, also after the laser action. In our work we demonstrated that proposed technique is promising for application in the fields of the prosthesis, restorative plastic materials, food and water container and other industries.

This work was supported by the "Research and Mobility" project of Messina University No. 74893496, scientifically coordinated by Professor L. Torrisi.

\section{References}

1. Friedrich G. Bachmann, Ulrich A. Russek, Laser Processing of Advanced Materials and Laser Microtechnologies, 385, (2003); DOI:10.1117/12.515630.

2. M Visco, G. Galtieri, L. Torrisi, C. Scolaro, A. Cannavò, IV ${ }^{\circ}$ PBSA 2014, 87-91, ISBN: 97888-8305-107-4.

3. A.M. Visco, V. Brancato, M. Cutroneo, C. Scolaro, F. Caridi and L. Torrisi, III ${ }^{\circ}$ PBSA 2012, 133-137, e-ISBN: 978-88-8305-088-6.

4. G. Galtieri, M Visco, D. Nocita, L. Torrisi, G. Ceccio, C. Scolaro, PPLA 2015, Journal of Scientific Instruments - IOPscience, 11 C04013, (2016) doi:10.1088/17480221/11/04/C04013.

5. V.V. Semak, R.J. Steele, P.W. Fuerschbach, J. of Physics D: Applied Physics, 33, 1179-1185 (2000).

6. F. Caridi, A. Picciotto, L. Vanzetti, E. Iacob, C. Scolaro, Radiation Physics and Chemistry 115, 49-54,

(2015), DOI:10.1016/j.radphyschem.2015.06.009.

7. S.C. Veerla, S. Spriano, A. Cochis, F. Uberti, L. Rimondini, E. Bertone, A. Vitale, C. Scolaro, M. Ferrari, F. Cirisano, G. Gautier di Confiengo, S. Ferraris Materials Science and Engineering C 74, 542-555(2017).

8. A.M. Visco, L. Torrisi, G. Galtieri, C. Scolaro, Journal of Thermoplastic Composite Materials, 1-18 (2016), DOI: $10.1177 / 0892705716662515$.

9. A.M. Visco, C. Scolaro, T. Terracciano, R. Montanini, A. Quattrocchi, L. Torrisi, N. Restuccia, PPLA2017, submitted at EPJ Web Conference. 
10. L. Torrisi, F. Caridi, A.M. Visco, N. Campo, Applied Surface Science, 257, 7, 2567-2575, (2011) DOI:10.1016/j.apscsc.2010.10.023.

11. L.Torrisi, C. Scolaro, N. Restuccia, J Mater Sci: Mater Med (2017) 28:63, DOI 10.1007/s10856017-5871-1.

12. Abraham Marmur, $A$ Guide to the Equilibrium Contact Angles Maze in Contact angle, Wettability and Adhesion, K.L. Mittal (Ed), 6:318, Vrill, Leiden (2009).

13. C. Scolaro, L. Torrisi, M. Cutroneo, L. Velardi, PPLA 2013, J. Phys.: Conf. Ser. 508012030 , (2014).

14. L. Torrisi, C. Scolaro, Journal of Thermodynamics \& Catalysis, 8:2, 184, (2017). DOI: $10.4179 / 2160-7544.1000184$.

15. Wenzel, R. N., "Resistance of solid surfaces to wetting by water". Ind. Eng. Chem. 28, 988994, 1936. DOI:10.1021/ie50320a024. 